\section{Limited Role of Cockcroft-Gault Formula in Dosing Information on Product Labels for Antineoplastic Drugs}

Creatinine clearance $(\mathrm{CrCl})$ is often used to determine initial dosing of renally excreted antineoplastic drugs. $\mathrm{CrCl}$ is typically estimated on the basis of serum creatinine, for which the Cockcroft-Gault formula is commonly used. ${ }^{1}$ It has been argued that dosing based on this formula should be held as the "gold standard" because it is the basis of information on product

Table 1. Types of Renal Dosing Information for Individual Drugs

\begin{tabular}{|c|c|c|}
\hline Drug & $\begin{array}{l}\text { Information on } \\
\text { Product Label* }\end{array}$ & $\begin{array}{c}\text { Basis of } \\
\text { Adjustment }\end{array}$ \\
\hline Azacitidine & Dose adjustments & BUN, $\mathrm{SrCr}$ \\
\hline Bleomycin & Dose adjustments & GFR \\
\hline Capecitabine & Dose adjustments & $\mathrm{CrCl}$ \\
\hline Carboplatin & Dose adjustments & $\mathrm{CrCl}$ \\
\hline Carmustine & Caution & NA \\
\hline Cisplatin & General dosing & $\mathrm{BUN}, \mathrm{SrCr}$ \\
\hline Cladribine & Caution & NA \\
\hline Cyclophosphamide & Dose adjustments & GFR \\
\hline Daunorubicin & Caution & $\mathrm{SrCr}$ \\
\hline Epirubicin & General dosing & $\mathrm{SrCr}$ \\
\hline Etoposide & Dose adjustments & $\mathrm{CrCl}$ \\
\hline Fludarabine & Dose adjustments & $\mathrm{CrCl}$ \\
\hline Gemcitabine & Caution & NA \\
\hline Hydroxyurea & Caution & $\mathrm{CrCl}$ \\
\hline Idarubicin & General dosing & $\mathrm{SrCr}$ \\
\hline Ifosfamide & Caution & NA \\
\hline Lenalidomide & Dose adjustments & $\mathrm{CrCl}$ \\
\hline Letrozole & General dosing & $\mathrm{CrCl}$ \\
\hline Lomustine & Caution & NA \\
\hline Melphalan & General dosing & BUN \\
\hline Mercaptopurine & No recommendation & NA \\
\hline Methotrexate & No recommendation & NA \\
\hline Mitomycin & General dosing & $\mathrm{SrCr}$ \\
\hline Oxaliplatin & General dosing & $\mathrm{CrCl}$ \\
\hline Pemetrexed & Dose adjustments & $\mathrm{CrCl}$ \\
\hline Raltitrexed & Dose adjustments & $\mathrm{CrCl}$ \\
\hline Streptozocin & Caution & NA \\
\hline Temozolomide & Caution & NA \\
\hline Topotecan & Dose adjustments & $\mathrm{CrCl}$ \\
\hline \multicolumn{3}{|c|}{$\begin{array}{l}\text { BUN = blood urea nitrogen, } \mathrm{CrCl}=\text { creatinine clearance, } \\
\text { GFR = glomerular filtration rate, } \mathrm{NA}=\text { not applicable, } \\
\mathrm{SrCr}=\text { serum creatinine. } \\
\text { * "Caution" signifies information such as "use with caution in } \\
\text { patients with renal impairment"; "general dosing" signifies } \\
\text { information such as "use lower dose if } \mathrm{CrCl}<40 \mathrm{~mL} / \mathrm{min}^{\prime} \text {; } \\
\text { "dose adjustments" signifies information such as "reduce } \\
\text { dose by } 50 \% \text { if } \mathrm{CrCl}<40 \mathrm{~mL} / \mathrm{min}^{\circ} \text {. }\end{array}$} \\
\hline
\end{tabular}

labels. ${ }^{2,3}$ To verify this claim, we reviewed the product labels of 29 antineoplastic drugs available in Canada for which dose adjustment is required for patients with impaired renal function (Table 1).

For $11(38 \%)$ of the drugs, the labels provided a general caution or no recommendation at all (Table 2), whereas for 7 (24\%), renal function was described in terms of serum creatinine or blood urea nitrogen. As such, the labels for only $11(38 \%)$ of the drugs provided specific information on renal dose adjustments (Table 2), and for only 2 drugs (capecitabine and pemetrexed) did the labels actually mention the CockcroftGault formula.

\section{Table 2. Summary of Renal Dosing Information}

\begin{tabular}{lcc} 
Dosing Information & $\begin{array}{c}\text { No. (\%) of Products } \\
(\boldsymbol{n}=\mathbf{2 9})\end{array}$ \\
\hline Caution & 9 & $(31)$ \\
\hline No recommendation & 2 & $(7)$ \\
\hline General dosing & 7 & $(24)$ \\
Overall & 2 & \\
Using CrCl* & \multicolumn{2}{c}{} \\
\hline Dose adjustments & 11 & $(38)$ \\
Overall & 8 & \\
$\quad$ Using $\mathrm{CrCl}^{*}$ & \multicolumn{3}{c}{}
\end{tabular}

$\mathrm{CrCl}=$ creatinine clearance.

*This represents a subset of "overall".

Overall, the product labels of $18(62 \%)$ of the reviewed drugs provided limited information on renal dosing or did not recommend use of $\mathrm{CrCl}$ for dose adjustments. Therefore, it seems reasonable to question the insistence on using only the Cockcroft-Gault formula for dosing of drugs in patients with renal impairment, except where specific supporting data are available (e.g., for capecitabine, pemetrexed).

References

1. Cockcroft DW, Gault MH. Prediction of creatinine clearance from serum creatinine. Nephron. 1976;16(1):31-41.

2. Holweger K, Lipp HP, Dietz K, Hartmann JT, Bokemeyer C. Novel algorithm for more accurate calculation of renal function in adults with cancer. Ann Pharmacother. 2008;42(12):1749-57.

3. Kleber M, Cybulla M, Bauchmüller K, Ihorst G, Koch B, Engelhardt M. Monitoring of renal function in cancer patients: an ongoing challenge for clinical practice. Ann Oncol. 2007;18(5):950-8.

Mário L de Lemos, PharmD, MSc(Oncol)

Provincial Drug Information Coordinator

Nadine Badry, BSc(Pharm)

Editor, Cancer Drug Manual

Linda Hamata, BSC(Pharm)

Staff Pharmacist

BC Cancer Agency

British Columbia

Competing interests: None declared. 